\title{
Genome Report: De novo genome assembly and annotation for the Taita white-eye (Zosterops silvanus)
}

Jan O. Engler ${ }^{1^{\star}}$, Yvonne Lawrie $^{1,2}$, Yannick Gansemans ${ }^{3}$, Filip Van Nieuwerburgh ${ }^{3}$, Alexander Suh $^{4,5}$, Luc Lens ${ }^{1}$

${ }^{1}$ Terrestrial Ecology Unit, Department of Biology, Ghent University, 9000 Ghent, Belgium

${ }^{2}$ School of Biological Sciences, University of Aberdeen, Aberdeen AB24 2TZ, U.K.

${ }^{3}$ Laboratory of Pharmaceutical Biotechnology, Faculty of Pharmaceutical Sciences, Ghent University, 9000 Ghent, Belgium

${ }^{4}$ Department of Ecology and Genetics - Evolutionary Biology, Uppsala University, Science for Life Laboratories, 75236 Uppsala, Sweden

${ }^{5}$ Department of Organismal Biology - Systematic Biology, Uppsala University, Science for Life Laboratories, 75236 Uppsala, Sweden

*Corresponding author: JanOliver.Engler@ugent.be

\section{Keywords:}

Zosterops silvanus, white-eyes, avian genome, supernova genome assembly, 10X Genomics

\section{Abstract}

The Taita White-eye (Zosterops silvanus) is an endangered songbird endemic to the Taita Hills of Southern Kenya, where it is confined to small areas of fragmented forest. With diversification rates exceeding those reported in most other vertebrates, White-eyes are a prime example of a 'great speciator'. Nevertheless, we still know surprisingly little 
about the genomic underpinnings leading to this extraordinary fast radiation. Here, we present a draft genome assembly (ZSil_MB_1.0) for the Taita White-eye generated from a blood sample of a wild, female bird captured in the Taita Hills, Kenya. By performing a de novo assembly with linked-reads and annotation of the assembly with the MAKER pipeline, we generated a $1.069 \mathrm{~Gb}$ assembly with a scaffold N50 of $1.105 \mathrm{Mb}$ and an L50 of 244 . After quality evaluation of the assembly, we identified $92.1 \%$ of BUSCOs complete or fragmented, indicating that our de novo assembly is of high quality. This new assembly provides a genomic resource for future studies into the evolutionary and comparative genomics of this rapidly diversifying group of birds.

\section{Introduction}

The Taita white-eye (Zosterops silvanus) is an East African highland songbird species endemic to the Taita Hills of Kenya, which has been subject to severe habitat loss over the past decades. The Taita White-eye is part of Zosteropidae, a unique family of birds known as "great speciators" (Diamond et al. 1976). Its most diverse genus Zosterops has one of fastest diversification rates among vertebrates, with over 100 species (and 250 sub-species; van Balen, 2019) emerging within the last 2.5 million years (Moyle et al. 2009). The phenotypic diversity in Zosterops is mostly conserved to a small body size and yellow-greenish colour patterns, even though aberrant phenotypes exist for some (mostly island endemic) taxa. With a lack of reference genomes available for this species and family as a whole, recent studies, such as on the silvereye (Zosterops lateralis, Cornetti et al. 2015) or the Mascarene grey white-eye (Z. borbonicus, Leroy et al. 2019) have demonstrated the relevance of generating genomic resources for this group of birds. Nevertheless, to further understand the rapid diversification in Zosterops more genomic resources from strategic phylogenetic positions would be highly important. 
Here, we describe ZSil_MB_1.0, a new genome assembly using DNA extracted from a wild, female Taita White-eye collected from the Mbololo forest fragment in the Taita Hills, Kenya. To generate this assembly, we used 10X Genomics Chromium linked reads and the Supernova assembler, following by analysis of the assembly using the assemblathon2 Perl script (Bradnam et al. 2013) and annotation using the MAKER2 pipeline (v 2.31.10, Holt \& Yandell 2011).

By generating the first de novo genome assembly for the Taita White-eye, we hope this will facilitate future research that aims to understand the underpinning of genotypic variation within this genus. In particular, identifying genomic regions under selection, which will greatly advance our understanding of the drivers of this radiation and help us to learn more about response to human activity and evolutionary constraints that might represent general features in other radiations too.

\section{Materials and Methods}

Genomic DNA Extraction and Genome Sequencing

We extracted genomic DNA from a blood sample of a female Taita White-eye captured on 15th July 1998 at the forest fragment of Mbololo in the Taita Hills, Kenya (ID: T29071_1006; GPS: 3¹9'37"S, 38²7'05"E). DNA extraction was done with a standard phenol-chloroform protocol (Sambrook et al. 1989). A single 10X Genomics Chromium linked-read sequencing library was generated and sequenced on an Illumina HiSeq $X$ instrument with 150-bp paired-end reads. In comparison to other short-read technologies, the Chromium system makes use of unique barcodes for each input DNA molecule which potentially allows for longer contigs and scaffolds of the assembly (Marks et al. 2019). Library preparation, sequencing and assembly - using the Supernova genome assembler for 10X Genomics (v. 1.1, Weisenfeld et al. 2017) - were performed at the National Genomics Infrastructure at SciLifeLab Stockholm, Sweden. 
Genome Assembly and Quality Check

We assessed the assembly quality using the assemblathon2 Perl script (assemblathon_stats.pl, Bradnam et al. 2015) slightly modified to be used in Strawberry Perl (64bit, v. 5.26.2.1) on a Windows 10 machine. Here, we include the following assembly statistics - for scaffolds and contigs respectively: the total number $(\mathrm{N})$, number > 1000 bp, N50, L50, a well as maximum, mean, median, and total length. In addition, we used BUSCO v. 3.0.1 (Simao et al. 2015) on an Oracle VM VirtualBox for Windows (BUSCO_3_Ubuntu_Gnome_16.04 accessible through busco.ezlab.org) to assess the gene set completeness. In our case, we used the "odb9_aves" dataset to check our assembly for 4915 avian single-copy orthologs. BUSCO classifies orthologs as complete and single-copy (S), complete but duplicated (D), fragmented (F) or as missing (M). For comparison, we calculated the same statistics also for the silvereye assembly (Cornetti et al. 2015).

\section{Genome Annotation}

Annotation of the white-eye genome was done using the MAKER2 pipeline (v2.31.10, Holt \& Yandell 2011). Briefly, this software starts by masking repeat sequences using RepeAtMasker (v4.0.7, Smit et al. 2017) with default settings. Next, MAKER2 uses protein sequences from related species to delineate homologous regions on the genome as candidate genes with BLASTX. We used protein sequences from chicken (Gallus gallus, NCBI GCF_000002315.4), turkey (Meleagris gallopavo, Ensembl UMD2), peregrine falcon (Falco peregrinus, NCBI GCF_000337955.1) and zebra finch (Taeniopygia guttata, Ensembl taeGut3.2.4). Then, the candidate gene sequences were retrieved from the genome and used to train a first $a b$ initio gene predictor. The trained predictor was then used by MAKER2 for discovery of additional gene candidates. The resulting gene 
candidates were again extracted from the genome and used to train the same predictor for refinement or a different predictor for more specificity, which was then used by MAKER2 to extend and improve the set of identified genes. At each round of this iterative process, MAKER2 calculated a quality metric for each gene. The ab initio predictors used in this study were: SNAP (v2013-02-16, Korf 2004), AUGUSTUS (v3.2.3, Stanke et al. 2006) and GeneMark (v4.32, Ter-Hovhannisyan et al. 2008). Transfer RNA genes were identified using tRNASCAN (v1.3.1, Lowe \& Eddy 1997) in a final MAKER2 pass. Protein domain and GO term information was added using INTERPROSCAN (v5.29, Jones et al. 2014). Ribosomal RNA genes were identified with RNAMmER (v1.2, Lagesen et al. 2007). Putative functions were assigned to candidate protein coding genes using BLASTP and the complete Swissprot/Uniprot database. For the mitochondrial genome, we identified the relevant scaffold by comparison to the available silvereye mitogenome (Cornetti et al. 2015) and annotation was done using the MITOS software (v2.0.1, Bernt et al. 2013). Finally, all genome annotation data of $Z$. silvanus was bundled in a single GFF3 file.

\section{Data availability}

Raw read data and the final assembly, ZSil_MB_1.0, are available from NCBI BioProject (PRJNA000000). Raw reads are available from NCBI SRA (XXX000000).

\section{Results and Discussion}

Sequencing of the 10X Chromium library produced 370.81 million read pairs with a mean input molecule length of $38.6 \mathrm{~kb}$ and a median insert size of $320 \mathrm{bp}$, resulting in a 45x depth of coverage. The ZSil_MB_1.0 Supernova assembly produced 101,111 contigs with a total length of $1.017 \mathrm{~Gb}$ and a contig N50 length of $34.2 \mathrm{~kb}$. The longest contig was 
290.6 kb. These contigs were joined by Supernova into 55,959 scaffolds totaling $1.069 \mathrm{~Gb}$ in length and a scaffold N50 length of $1.105 \mathrm{Mb}$ (Table 1). The longest scaffold was 8.001 Mb. For comparison, the silvereye assembly had a scaffold N50 length of $3.581 \mathrm{Mb}$ and a contig N50 length of $41.7 \mathrm{~kb}$ (Cornetti et al. 2015), and the Mascarene grey white-eye had a scaffold N50 length of $1.763 \mathrm{Mb}$ and a contig N50 length of $20.9 \mathrm{~kb}$ (Leroy et al. 2019). BUSCO scores indicated a high completeness with $92.1 \%$ of complete or fragmented single-copy orthologs and $7.1 \%$ missing orthologs for our Taita White-eye assembly (Table 2; compared to $96.1 \% / 2.9 \%$ for the silvereye and $97.3 \% / 2.5 \%$ for the Mascarene grey white-eye). The rate of duplicated orthologs was very low with $0.8 \%$ ( $1 \%$ for the silvereye). High BUSCO gene completeness has been found in most bird genomes (Peñalba et al. 2019) even though noticeable variation can be apparent among different assembly techniques and sequencing technologies (Peñalba et al. 2019, Peona et al. 2019). We therefore expect our BUSCO values to further improve in future assembly versions.

The final genome annotation using the MAKER2 pipeline revealed 18,033 candidate genes, of which 17,678 are potentially protein coding and of which 16,516 have been assigned with a putative function. Comparison of the protein-encoded genes having a known function with those extracted from the silvereye genome annotation (Cornetti et al. 2015) reveals 15,902 shared genes between the two species. Another 614 proteincoding genes with known function were only found in the Taita white-eye genome annotation, compared to 6,358 protein-coding genes solely found in the silvereye (Figure $1)$.

Linked-read sequencing has a huge potential for generating decent draft bird genome assemblies (Toomey et al. 2018, Boman et al. 2019, Kinsella et al. 2019, Lutgen et al. 2020). 10X Genomics Chromium is the most commonly used linked-read library preparation at present, but other linked-read methods (Chen et al. 2019, Redin et al. 2019) are equally promising but have yet to be tested on birds. Furthermore, the linked-read 
technology is still very new with ongoing developments and improvements of analytical tools and algorithms constantly being made. For instance, after the initial release of the Supernova assembly algorithm by 10X Genomics (v.1.1, Weisenfeld et al. 2017 - used in this report) there was a major update ( $v 2 . x)$ after finalizing our analyses. In addition, further assemblers (e.g., ARCS, Yeo et al. 2017 CLOUDSPADES, Tolstoganov et al. 2019, SLR-SUPERSCAFFOLDER, Deng et al. 2019) and tools for downstream analyses (e.g. TIGMINT, Jackman et al. 2018) recently emerged to improve such linked-read assemblies which might yield profound improvements of future versions of our draft assembly. Together in combination with other sequencing technologies such as $\mathrm{Hi}-\mathrm{C}$ or long-reads (Peona et al. 2018), there is certainly room for further improvements towards a reference genome. Nevertheless, the current draft assembly ZSil_MB_1.0 marks an essential progress towards unraveling the genomic basis of diversification in a 'great speciator' system.

\section{Acknowledgments}

The work was funded by the Research Foundation - Flanders (FWO; 1527918N \& G042318N) to LL and JOE, and a SciLifeLab Swedish Biodiversity Program grant (2015R14) to AS. JOE received additional funds by an FWO Postdoctoral Fellowship (12G4317N). The authors would like to thank Max Käller, Remi-André Olsen, and Joel

Gruselius at SciLifeLab Stockholm, Sweden for conducting library preparation, sequencing, and assembly, as well as Viki Vandomme and Hans Matheve for managing the sample collection at the Terrestrial Ecology Unit, Ghent University. The authors acknowledge support from the National Genomics Infrastructure in Stockholm funded by Science for Life Laboratory, the Knut and Alice Wallenberg Foundation and the Swedish Research Council, and SNIC/Uppsala Multidisciplinary Center for Advanced 
Computational Science for assistance with massively parallel sequencing and access to the UPPMAX computational infrastructure. For comparison of the predicted white-eye proteins to those of the silvereye, we used its genome-derived peptide sequences and GFF3 file which were kindly supplied by Luca Cornetti.

JOE and LL conceptualized the research; YG and JOE performed analyses with critical input from FVN and AS; JOE and YL wrote the paper with critical feedback from all authors; JOE, AS, LL secured funding; all authors reviewed and approved the final manuscript.

\section{Literature cited}

Bernt M, Donath A, Juhling F, Externbrink F, Florentz C, Fritzsch G, Putz J, Middendorf M, Stadler PF 2013 MITOS: improved de novo metazoan mitochondrial genome annotation. Molecular Phylogenetics and Evolution 69:313-319.

Bradnam KR, Fass JN, Alexandrov A, Baranay P, Bechner M, Birol I, Boisvert S, Chapman JA, Chapuis G, Chikhi R, Chitsaz H, Chou WC, Corbeil J, Del Fabbro C, Docking TR, Durbin R, Earl D, Emrich S, Fedotov P, Fonseca NA, Ganapathy G, Gibbs RA, Gnerre S, Godzaridis E, Goldstein S, Haimel M, Hall G, Haussler D, Hiatt JB, Ho IY, Howard J, Hunt M, Jackman SD, Jaffe DB, Jarvis ED, Jiang H, Kazakov S, Kersey PJ, Kitzman JO, Knight JR, Koren S, Lam TW, Lavenier D, Laviolette F, Li Y, Li Z, Liu B, Liu Y, Luo R, Maccallum I, Macmanes MD, Maillet N, Melnikov S, Naquin D, Ning Z, Otto TD, Paten B, Paulo OS, Phillippy AM, Pina-Martins F, Place M, Przybylski D, Qin X, Qu C, Ribeiro FJ, Richards S, Rokhsar DS, Ruby JG, Scalabrin S, Schatz MC, Schwartz DC, Sergushichev A, Sharpe T, Shaw TI, Shendure J, Shi Y, Simpson JT, Song H, Tsarev F, Vezzi F, Vicedomini R, Vieira BM, Wang J, Worley KC, Yin S, Yiu SM, Yuan J, Zhang G, Zhang H, Zhou S, Korf IF, 2013 Assemblathon 2: evaluating de novo methods of genome assembly in three vertebrate species. Gigascience Jul 22;2(1):10.

Boman J, Frankl-Vilches C, da Silva dos Santos M, de Oliveira EHC, Gahr M, Suh A 2019 The genome of the blue-capped cordon-bleu uncovers hidden diversity of LTR retrotransposons in zebra finch. Genes 10:301.

Chen Z, Pham L, Wu TC, Mo G, Xia Y, Chang P, Porter D, Phan T, Che H, Tran H, Bansal V, Shaffer J, Belda-Ferre P, Humphrey G, Knght R, Pevzner P, Pham S, Wang Y, Lei M, 2019 Ultra-low input single tube linked-read library method enables short-read NGS systems to generate highly accurate and economical long-range sequencing information for de novo genome assembly and haplotype phasing. BioRxiv 852947. 
Cornett L, Valente LM, Dunning LT, Quan X, Black RA, Hébert O, Savolainen V, 2015 The Genome of the "Great Speciator" Provides Insights into Bird Diversification. Genome Biology and Evolution 7: 2680-2691.

Deng L, Guo L, Xu M, Wang W, Gu S, Zhao X, Chen F, Wang O, Xu X, Fan G, Liu X, 2019 SLR-superscaffolder: a de novo scaffolding tool for synthetic long reads using a top-tobottom scheme. BioRxiv 762385.

Diamond JM, Gilpin ME, Mayr E, 1976 Species-distance relation for birds of the Solomon Archipelago, and the paradox of the great speciators. Proceedings of the National Academy of Sciences of the United States of America 73:2160-2164.

Holt C, Yandell M, 2011 MAKER2: an annotation pipeline and genome-database management tool for second-generation genome projects. BMC Bioinformatics 12:491.

Jackman SD, Coombe L, Chu J, Warren RL, Vandervalk BP, Yeo S, Xue Z, Mohamadi H, Bohlmann J, Jones SJM, Birol I, 2018 Tigmint: correcting assembly errors using linked reads from large molecules. BMC Bioinformatics 19: 393.

Jones $P$, Binns D, Chang H-Y, Fraser M, Li W, McAnulla C, McWilliam H, Maslen J, Mitchell A, Nuka G, Pesseat S, Quinn AF, Sangrador-Vegas A, Scheremetjew M, Yong SY, Lopez R, Hunter S, 2014 InterProScan 5: genome-scale protein function classification. Bioinformatics. 30:1236-1240.

Kinsella CM, Ruiz-Ruano FJ, Dion-Côté AM, Charles AJ, Gossmann TI, Cabrero J, Kappei D, Hemmings N, Simons MJP, Camacho JPM, Forstmeier W, Suh A 2019 Programmed DNA elimination of germline development genes in songbirds. Nature Communications 10:5468.

Korf I, 2004 Gene finding in novel genomes. BMC Bioinformatics 5:59

Lagesen K, Hallin P, Rodland EA, Staerfeldt HH, Rognes T, Ussery DW, 2007 RNAmmer: consistent and rapid annotation of ribosomal RNA genes. Nucleic Acids Research 35, 3100-3108.

Leroy T, Anselmetti Y, Tilak MK, Bérard S, Csukomyi L, Gabrielli M, Scornavacca C, Mila B, Thebaud C, Nabholz B. 2019 A bird's white-eye view on neosex chromosome evolution. BioRxiv 505610.

Lowe TM, Eddy SR, 1997 tRNAscan-SE: a program for improved detection of transfer RNA genes in genomic sequence. Nucleic Acids Res. 25:955-964.

Lukashin AV, Borodovsky M, 1998 GeneMark.hmm: new solutions for gene finding. Nucleic Acids Research 26:1107-1115 
Lutgen D, Ritter R, Olsen RA, Schielzeth H, Gruselius J, Ewels P, García JT, Shirihai H, Schweizer M, Suh A, Burri R, 2020 Linked-read sequencing enables haplotyperesolved resequencing at population scale. BioRxiv 907261.

Marks P, Garcia S, Barrio AM, Belhocine K, Bernate J, Bharadwaj R, Bjornson K, Catalanotti C, Delaney J, Fehr A, Fiddes IT, Galvin B, Heaton H, Herschleb J, Hindson C, Holt E, Jabara CB, Jett S, Keivanfar N, Kyriazopoulou-Panagiotopoulou S, Lek M, Lin B, Lowe A, Mahamdallie S, Maheshwari S, Makarewicz T, Marshall J, Meschi F, O'Keefe CJ, Ordonez H, Patel P, Price A, Royall A, Ruark E, Seal S, Schnall-Levin M, Shah P, Stafford D, Williams S, Wu I, Xu AW, Rahmann N, MacArthur D, Church DM, 2019 Resolving the full spectrum of human genome variation using Linked-Reads. Genome Research. 29, 635-645.

Moyle RG, Filardi CE, Smith CE, Diamond J, 2009 Explosive Pleistocene diversification and hemispheric expansion of a "great speciator". Proceedings of the National Academy of Sciences of the United States of America. 106, 1863-1868.

Peñalba JV, Deng Y, Fang Q, Joseph L, Moritz C, Cockburn A 2019 Genome of an iconic Australian bird: High-quality assembly and linkage map of the superb fairy-wren (Malurus cyaneus). Molecular Ecology Resources doi:10.1111/1755-0998.13124.

Peona V, Weissensteiner MH, Suh A 2018 How complete are "complete" genome assemblies?-An avian perspective. Molecular Ecology Resources 18:1188-1195.

Peona V, Blom MPK, Xu L, Burri R, Sullivan S, Bunikis I, Liachko I, Jønsson KA, Zhou Q, Irestedt M, Suh A 2019 Identifying the causes and consequences of assembly gaps using a multiplatform genome assembly of a bird-of-paradise. BioRxiv 882399.

Quevillon E, Silventoinen V, Pillai S, Harte N, Mulder N, Apweiler R, Lopez R, 2005 InterProScan: protein domains identifier. Nucleic acids research 33

Redin D, Frick T, Aghelpasand H, Käller M, Borgström E, Olsen RA, Ahmadian A, 2019 High throughput barcoding method for genome-scale phasing. Scientific Reports 9:18116.

Sambrook J, Fritsch EF, Maniatis T, 1989 Molecular Cloning: A Laboratory Manual. Cold Spring Harbor Laboratory Press, Nova York.

Simão FA, Waterhouse RM, Ioannidis P, Kriventseva EV, Zdobnov EM, 2015 BUSCO: assessing genome assembly and annotation completeness with single-copy orthologs. Bioinformatics 31: 3210-3212.

Smit, AFA, Hubley, R, Green P, 2017 RepeatMasker Open-4.0.7, www.repeatmasker.org.

Stanke M, Keller O, Gunduz I, Hayes A, Waack S, Morgenstern B, 2006 AUGUSTUS: ab initio prediction of alternative transcripts. Nucleic Acids Res. 34:W435-W439. 
Ter-Hovhannisyan V, Lomsadze A, Chernoff YO, Borodovsky M, 2008 Gene prediction in novel fungal genomes using an ab initio algorithm with unsupervised training. Genome Res. 18:1979-1990.

Tolstoganov I, Bankevich A, Chen Z, Pevzner PA, 2019 cloudSPAdes: assembly of synthetic long reads using de Bruijn graphs. Bioinformatics 35: i61-i70.

Toomey MB, Marques CI, Andrade P, Araújo PM, Sabatino S, Gazda MA, Afonso S, Lopes RJ, Corbo JC, Carneiro M, 2018. A non-coding region near Follistatin controls head colour polymorphism in the Gouldian finch. Proceedings R Soc B 285: 20181788.

van Balen B. Rennell White-eye (Zosterops rennellianus). In: del Hoyo J, Elliott A, Sargatal $J$, Christie DA, de Juana E (eds.). Handbook of the Birds of the World Alive. Lynx Edicions, Barcelona. (retrieved from https://www.hbw.com/node/60199 on 16th November 2019).

Weisenfeld NI, Kumar V, Shah P, Church DM, Jaffe DB, 2017 Direct determination of diploid genome sequences. Genome Research 10.1101/gr.214874.116.

Yeo S, Coombe L, Warren RL, Chu J, Birol I, 2017 ARCS: scaffolding genome drafts with linked reads. Bioinformatics 34: 725-731.

Zdobnov EM, Apweiler R, 2001 InterProScan-an integration platform for the signaturerecognition methods in InterPro. Bioinformatics 17:847-848 
bioRxiv preprint doi: https://doi.org/10.1101/2020.03.06.980599; this version posted March 7, 2020. The copyright holder for this preprint (which was not certified by peer review) is the author/funder, who has granted bioRxiv a license to display the preprint in perpetuity. It is made available under aCC-BY-NC-ND 4.0 International license.

Table 1: Standard assembly metrics for scaffolds and contigs using the Supernova assembler including the total number $(\mathrm{N})$, number longer than $1000 \mathrm{bp}(\mathrm{N}>1000)$, N50 and L50, as well as maximum, mean, median, and total length.

\begin{tabular}{l|rr}
\hline Assembly statistic & Scaffolds & Contigs \\
\hline $\mathrm{N}$ & 55,959 & 101,111 \\
$\mathrm{~N}>1000$ & 55,920 & 88,537 \\
$\mathrm{~N} 50$ & $1,104,592$ & 34,226 \\
$\mathrm{~L} 50$ & 244 & 8,377 \\
Max length & $8,001,144$ & 290,647 \\
Mean length & 19,113 & 10,065 \\
Median length & 2,195 & 2,773 \\
\hline Total length & $1,069,554,122$ & $1,017,729,102$ \\
\hline
\end{tabular}


bioRxiv preprint doi: https://doi.org/10.1101/2020.03.06.980599; this version posted March 7, 2020. The copyright holder for this preprint (which was not certified by peer review) is the author/funder, who has granted bioRxiv a license to display the preprint in perpetuity. It is made available under aCC-BY-NC-ND 4.0 International license.

Table 2: Assessment of the Supernova genome assembly and annotation completeness with BUSCO.

\begin{tabular}{l|ll}
\hline BUSCO scores & $\mathbf{n}$ & $\%$ \\
\hline Complete single copy & 4176 & 85 \\
Complete duplicated & 39 & 0.8 \\
Fragmented & 347 & 7.1 \\
Missing & 353 & 7.2 \\
\hline
\end{tabular}




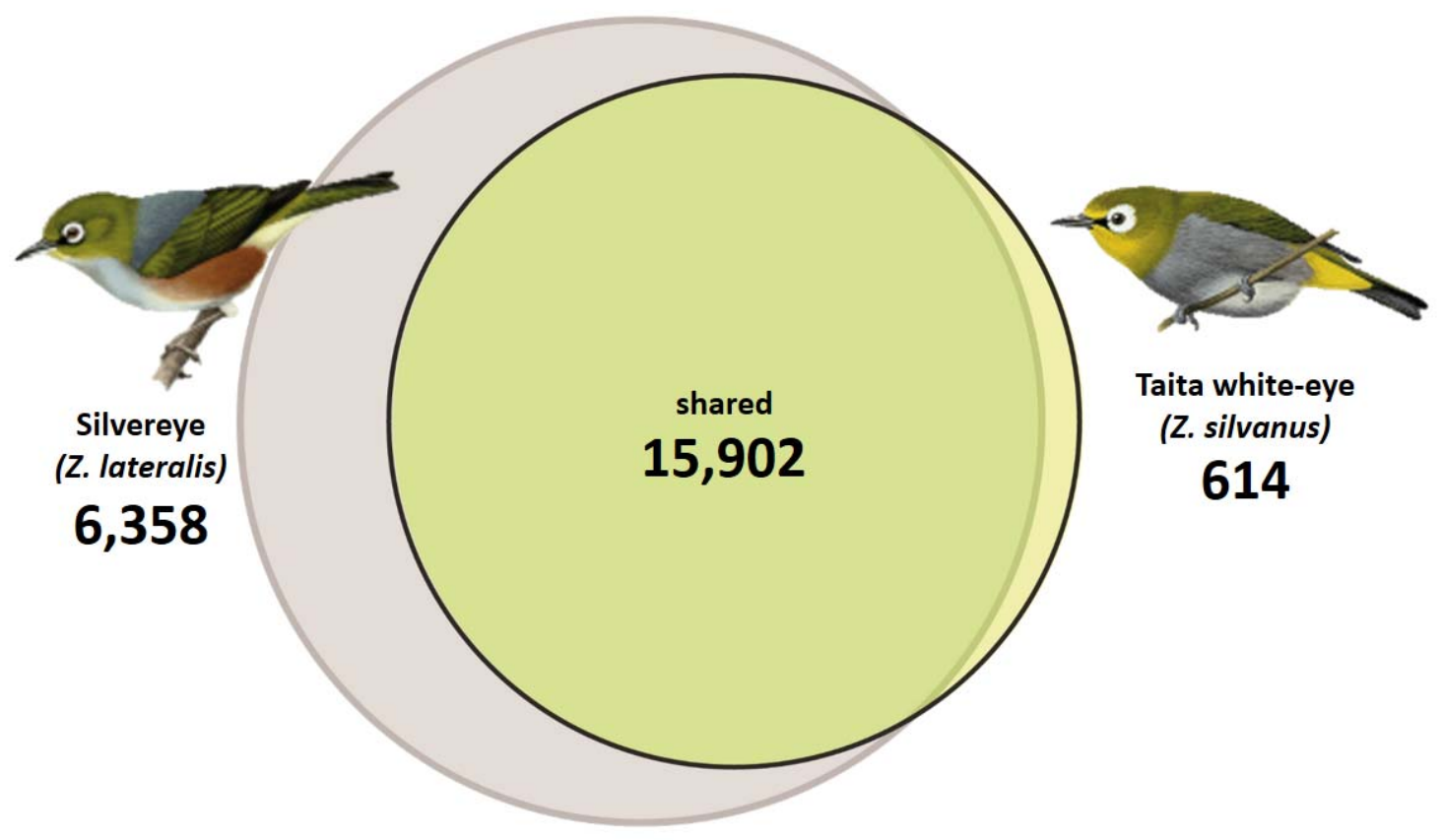

Figure 1: Venn diagram of predicted genes with putative protein function unique for as well as shared between the Taita white-eye (Zosterops silvanus, yellow circle) and the silvereye ( $Z$. lateralis, grey circle) genome assemblies. Illustrations curtesy of HBWalive. 